See discussions, stats, and author profiles for this publication at: https://www.researchgate.net/publication/26803476

\title{
Trial of 2009 Influenza A (H1N1) Monovalent MF59-Adjuvanted Vaccine
}

Article in New England Journal of Medicine · September 2009

DOI: 10.1056/NEJMoa0907650 · Source: PubMed

7 authors, including:

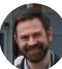

Tristan William Clark

University of Southampton

75 PUBLICATIONS 1,641 CITATIONS

SEE PROFILE

Helen Dillon

South Warwickshire NHS Foundation Trust

5 PUBLICATIONS 493 CITATIONS

SEE PROFILE
Katja Hoschler

Public Health England

109 PUBLICATIONS 8,858 CITATIONS

SEE PROFILE

Nicola Groth

GSK Vaccines, Siena, Italy

54 PUBLICATIONS 2,219 CITATIONS

SEE PROFILE

Some of the authors of this publication are also working on these related projects:

Project Wellbeing and quality of life View project

Project Influenza immunization View project 
ORIGINAL ARTICLE

\section{Trial of Influenza A (H1N1) 2009 Monovalent MF59-Adjuvanted Vaccine - Preliminary Report}

Tristan W. Clark, M.R.C.P., Manish Pareek, M.R.C.P., Katja Hoschler, Ph.D., Helen Dillon, M.R.C.P., Karl G. Nicholson, M.D., F.R.C.P., Nicola Groth, M.D., and Iain Stephenson, M.D., F.R.C.P.

A BSTRACT

\section{BACKGROUND}

The 2009 pandemic influenza A (H1N1) virus has emerged to cause the first pandemic of the 21st century. Development of effective vaccines is a public health priority.

\section{METHODS}

We conducted a single-center study, involving 175 adults, 18 to 50 years of age, to test the monovalent influenza A/California/2009 (H1N1) surface-antigen vaccine, in both MF59-adjuvanted and nonadjuvanted forms. Subjects were randomly assigned to receive two intramuscular injections of vaccine containing $7.5 \mu \mathrm{g}$ of hemagglutinin on day 0 in each arm or one injection on day 0 and the other on day 7, 14, or 21; or two 3.75- $\mu \mathrm{g}$ doses of MF59-adjuvanted vaccine, or 7.5 or $15 \mu \mathrm{g}$ of nonadjuvanted vaccine, administered 21 days apart. Antibody responses were measured by means of hemagglutination-inhibition assay and a microneutralization assay on days $0,14,21$, and 42 after injection of the first dose.

\section{RESULTS}

Results of an interim analysis of the responses to the 7.5- $\mu$ g dose of MF59-adjuvanted vaccine by days 14 and 21 are presented (data from four of the seven groups studied, for a total of 100 subjects). The most frequent local and systemic reactions were pain at the injection site and muscle aches, noted in $70 \%$ and $42 \%$ of subjects, respectively. Two subjects reported fever, with a temperature of $38^{\circ} \mathrm{C}$ or higher, after the first dosing. Antibody titers, expressed as geometric means, were generally higher at day 14 among subjects who had received two 7.5- $\mu$ g doses of the MF59-adjuvanted vaccine than among those who had received only one by this time point $(\mathrm{P}=0.04$ by the hemagglutination-inhibition assay and $\mathrm{P}<0.001$ by the microneutralization assay). By 21 days after vaccination with the first dose of $7.5 \mu \mathrm{g}$ of MF59-adjuvanted vaccine, the rates of seroconversion, as measured with the use of a hemagglutination-inhibition assay and a microneutralization assay, were $76 \%$ and $92 \%$ of subjects, respectively, who had received only one dose to date (with the second dose scheduled for day 21) and 88 to $92 \%$ and 92 to $96 \%$ of subjects, respectively, who had already received both doses $(\mathrm{P}=0.11$ and $\mathrm{P}=0.64$, respectively).

\section{CONCLUSIONS}

In preliminary analyses, the monovalent influenza A (H1N1) 2009 MF59-adjuvanted vaccine generates antibody responses likely to be associated with protection within 14 days after a single dose is administered. (ClinicalTrials.gov number, NCT00943358.)
From the Infectious Diseases Unit, University Hospitals Leicester and Department of Inflammation, Infection and Immunity, University of Leicester, Leicester, United Kingdom (T.W.C., M.P., H.D., K.G.N., I.S.); the Respiratory Virus Laboratory, Health Protection Agency, London (K.H.); and Novartis Vaccines and Diagnostics, Siena, Italy (N.G.). Address reprint requests to Dr. Stephenson at the Infectious Diseases Unit, Level 6, Windsor Bldg., Leicester Royal Infirmary, Leicester, United Kingdom, or at iain.stephenson@ uhl-tr.nhs.uk.

Drs. Clark and Pareek contributed equally to this article.

This article (10.1056/NEJMoa0907650) was published on September 10, 2009, at NEJM.org.

N EnglJ Med 2009;361

Copyright $(2009$ Massachusetts Medical Society. 
T HE EMERGENCE OF THE 2009 PANDEMIC influenza A (H1N1) virus demonstrates the unpredictable nature of influenza. ${ }^{1}$ The 2009

$\mathrm{H} 1 \mathrm{~N} 1$ virus has the potential to cause disease, death, and socioeconomic disruption, ${ }^{2,3}$ and mathematical modeling suggests that the effect of the virus can be reduced by immunization. ${ }^{4}$ The development of effective vaccines is a public health priority.

Traditional seasonal influenza vaccines are produced from reassortant vaccine strains grown in hens' eggs. However, demand for vaccine against the 2009 H1N1 virus will exceed the supply if this method of manufacturing is used. Cell culture provides an alternative platform for the manufacture of influenza vaccines that may be more easily scaled up during a period of heightened demand. 5-7

Serologic analysis suggests that after seasonal vaccination in children and adults under 50 years of age, there is little evidence of cross-reactive antibodies against the $2009 \mathrm{H} 1 \mathrm{~N} 1$ virus, ${ }^{8}$ with no evidence of protection from the seasonal vaccine. ${ }^{9}$ The efficacy of conventional vaccines prepared from avian influenza strains is disappointingly low in subjects who have little evidence of crossreactive antibodies, even if two doses are given. ${ }^{10-14}$ The addition of oil-in-water-emulsion adjuvant enhances immunogenicity and induces cross-reactive antibodies against antigenically drifted variants. ${ }^{12-16}$ The use of such adjuvants in influenza A (H1N1) 2009 vaccines has been suggested by the World Health Organization. ${ }^{17}$

Preparations for influenza A (H1N1) 2009 vaccination programs are under way, but the optimal formulation is unknown. The need for highyield vaccine strains, limitations of the supply and production capacity of egg-based vaccines, and an expected requirement for a two-dose vaccine schedule may delay an effective immunization program.

In this preliminary report, we present the clinical-event and immunogenicity profiles of the $7.5-\mu \mathrm{g}$ dose of the monovalent influenza A/ California/2009 (H1N1) MF59-adjuvanted surfaceantigen vaccine, derived from cell culture, administered to adults 18 to 50 years of age. Two doses of the vaccine were either given concurrently, one in each arm, on day 0 or one dose was given on day 0 and the other on day 7 or 14 . We will update this report with findings from subjects given two doses of $3.75 \mu \mathrm{g}$ or $7.5 \mu \mathrm{g}$ of MF59adjuvanted vaccine, or $7.5 \mu \mathrm{g}$ or $15 \mu \mathrm{g}$ of nonadju- vanted vaccine, given 21 days apart, once these data are available.

METHODS

The study was designed by one academic author and one industry author; the academic author was responsible for data management and drafting the manuscript. The data were fully accessible and interpreted by all the authors, who vouch for the accuracy and completeness of the data and analyses. The U.K. Medicines and Healthcare Products Regulatory Agency and the Leicestershire, Rutland, and Northamptonshire Ethics Committee approved the study. University Hospitals Leicester was the main sponsor; the vaccine was manufactured by Novartis, who provided funding but had no role in the conduct of the study or in preparation of the manuscript.

\section{VACCINE}

The 2009 H1N1 vaccine virus (New York Medical College [NYMC] X-179A) was generated from the influenza A/California/7/2009 strain with the use of classical reassortant methods. The gene segments encoding the hemagglutinin, neuraminidase, and the polymerase PB1 were derived from the influenza A/California/7/2009 strain, with the remaining genes taken from the influenza $\mathrm{A} /$ PR8/8/34 virus used as a backbone for influenza vaccines. The strain was supplied by the Centers for Disease Control and Prevention and is a pandemic vaccine strain recommended for use in vaccine development. The seed virus was grown in Madin-Darby Canine Kidney (MDCK) cell culture by means of standard processes similar to those used for the development of Optaflu vaccines against interpandemic influenza. The vaccine was formulated and produced by Novartis (Marburg, Germany) as an inactivated surface-antigen H1N1 vaccine, with or without MF59 adjuvant, and supplied in 0.5 -ml prefilled single-dose syringes. Each MF59-adjuvanted vaccine contained $7.5 \mu \mathrm{g}$ of $\mathrm{H} 1$ hemagglutinin, $9.75 \mathrm{mg}$ of the squalene MF59, $1.175 \mathrm{mg}$ of polysorbate 80 , and $1.175 \mathrm{mg}$ of sorbitan trioleate in buffer. Each nonadjuvanted vaccine contained $15 \mu \mathrm{g}$ of $\mathrm{H} 1$ hemagglutinin in buffer. Hemagglutinin content in the final vaccine was determined by means of reverse-phase highperformance liquid chromatography, because single-radial diffusion reagents were unavailable. Vaccine was stored at $4^{\circ} \mathrm{C}$ until use. 


\section{STUDY DESIGN}

We conducted a single-center, phase 1 , randomized study from July through September 2009 at Leicester Royal Infirmary (Leicester, United Kingdom). Subjects were screened for eligibility and provided written informed consent. (For eligibility criteria, see the Supplementary Appendix, available with the full text of this article at NEJM.org.)

The first 100 subjects enrolled were randomly assigned, in a 1:1:1:1 ratio (in five blocks of 20 subjects), to receive two doses of $7.5 \mu \mathrm{g}$ of MF59adjuvanted vaccine, either concurrently administered on day 0 (i.e., one injection of the vaccine containing twice the antigen and adjuvant content of a single vaccine) or administered in two doses, one at day 0 and the other at day 7,14 , or 21. Serum samples for antibody measurements were collected on days $0,14,21$, and 28 . We present here the data from interim analyses performed at day 21 for these first 100 subjects.

The remaining 75 subjects enrolled were randomly assigned, in a 1:1:1 ratio (in five blocks of 15 subjects), to receive two doses of $3.75 \mu \mathrm{g}$ of MF59-adjuvanted vaccine (by administering half the contents of the adjuvanted-vaccine syringe for each), two $15-\mu \mathrm{g}$ doses of nonadjuvanted vaccine, or two $7.5-\mu \mathrm{g}$ doses of nonadjuvanted vaccine (by administering half the contents of the nonadjuvanted-vaccine syringe for each) - with one injection at day 0 and the other at day 21. Serum samples were collected on days $0,14,21$, and 42 . The results for these subjects will be reported when analyses are completed.

The vaccine was administered by intramuscular injection into the deltoid muscle of the nondominant arm, or in both arms if both doses were given on day 0 . Subjects were observed for $30 \mathrm{~min}$ utes after each injection, and for the next 7 days they recorded, in self-completed diaries, the severity of unsolicited and solicited local symptoms (pain, bruising, erythema, and swelling) and systemic symptoms (chills, malaise, muscle aches, nausea, and headache), oral temperature, and use of analgesics. Symptoms were graded as follows: none; mild, if they did not interfere with normal activities; moderate, if they resulted in interference with normal activities; and severe, if they prevented engagement in daily activities and necessitated medical attention. Serious adverse reactions were defined as any reaction that persisted beyond 7 days after vaccination or that necessitated medical attention or hospitalization during the study period.

\section{LABORATORY ASSAYS}

Antibody responses were detected by means of microneutralization and hemagglutination-inhibition assays, according to standard methods, ${ }^{18,19}$ at the Centre for Infections, Health Protection Agency (London), and with the use of cell-culture $X-179 A$ H1N1 vaccine (see the Vaccine section above), egg-grown NIBRG-121 virus, and a reverse-genetic virus containing hemagglutinin and neuraminidase from the influenza A/California/7/2009 strain (see the Supplementary Appendix for details). Serum samples obtained from subjects were tested with the use of 1:2 serial dilutions. For hemagglutination-inhibition assays, serum samples were tested at an initial dilution of $1: 8$, and those that were negative for the hemagglutinin antibody were assigned a titer of 1:4. Serum specimens were analyzed to determine absolute end-point titers, and the final dilution was 1:32,768. For microneutralization assays, serum samples were tested at an initial dilution of $1: 10,{ }^{20}$ and those that were negative were assigned a titer of 1:5. The final dilution was 1:320, and samples for which the end-point titers were greater were assigned a value of 1:640. Specimens were tested in duplicate, and the geometric mean values were used in analyses.

\section{STATISTICAL ANALYSIS}

The group sizes in our study are usual for phase 1 studies and were not based on power calculations. This preliminary report details the results of analyses of data from subjects who received $7.5 \mu \mathrm{g}$ of MF59-adjuvanted vaccine. Data analysis was undertaken with the use of Stata software (version 9.2, StataCorp).

For solicited and unsolicited adverse reactions, the percentages of subjects (point estimates and 95\% confidence intervals) with postvaccination reactions were based on the frequency and severity of the reported responses after vaccination. Exact (Clopper-Pearson) confidence intervals are reported for all proportional end points. We used a two-sided Fisher's exact test to compare proportions between vaccine groups. All reported $\mathrm{P}$ values are two-sided, with no adjustment for multiple testing; values of 0.05 or less were considered to indicate statistical significance.

For immunogenicity analyses, the geometric mean antibody titers at each time point were used. Geometric mean titers and 95\% confidence intervals were computed by taking the exponent $\left(\log _{10}\right)$ of the mean and of the lower and upper 


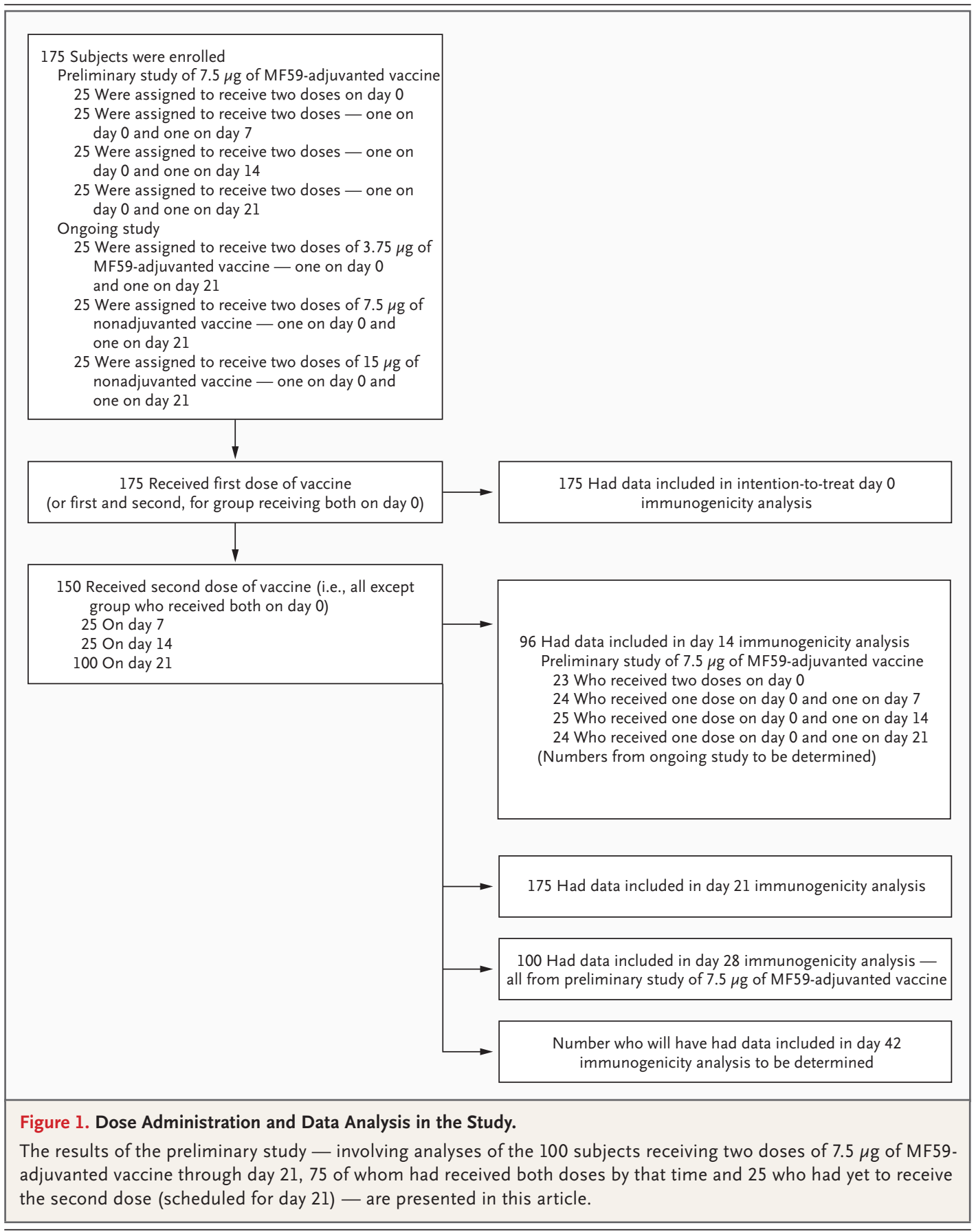

limits of the $95 \%$ confidence intervals of the $\log _{10}$-transformed titers. Geometric mean titers were compared between each pair of vaccine groups by means of one-way analysis of variance on the $\log _{10}$-transformed titers with Bonferroni correction for multiple pairwise comparisons, if appropriate. The proportions of subjects in whom seroconversion (a prevaccination hemagglutina- tion-inhibition antibody titer $\leq 1: 10$ and a postvaccination titer $\geq 1: 40$ or a prevaccination titer $\geq 1: 10$ and an increase in the titer by a factor of four or more) or seroprotection (a hemagglutinininhibition antibody titer $\geq 1: 40$ ) was achieved were compared between each group with the use of a two-sided Fisher's exact test. Separate analyses were performed for the hemagglutination- 


\begin{tabular}{|c|c|c|c|c|c|c|c|}
\hline \multirow[t]{3}{*}{ Characteristic } & \multicolumn{5}{|c|}{ MF59-Adjuvanted Vaccine } & \multicolumn{2}{|c|}{ Nonadjuvanted Vaccine } \\
\hline & \multirow[b]{2}{*}{$\begin{array}{l}\text { Both Doses, } \\
\text { Day } 0 \\
(\mathrm{~N}=25)\end{array}$} & \multicolumn{2}{|c|}{$7.5 \mu \mathrm{g}$} & \multirow[b]{2}{*}{$\begin{array}{c}\text { One Dose } \\
\text { on Day 0, } \\
\text { One on Day } 21 \\
(\mathrm{~N}=25)\end{array}$} & \multirow{2}{*}{$\begin{array}{c}3.75 \mu \mathrm{g} \\
\text { One Dose } \\
\text { on Day 0, } \\
\text { One on Day } 21 \\
(\mathrm{~N}=25)\end{array}$} & \multirow{2}{*}{$\begin{array}{c}7.5 \mu \mathrm{g} \\
\text { One Dose } \\
\text { on Day 0, } \\
\text { One on Day } 21 \\
(\mathrm{~N}=25)\end{array}$} & \multirow{2}{*}{$\begin{array}{c}15 \mu \mathrm{g} \\
\text { One Dose } \\
\text { on Day 0, } \\
\text { One on Day } 21 \\
(\mathrm{~N}=25)\end{array}$} \\
\hline & & $\begin{array}{c}\text { One Dose } \\
\text { on Day 0, } \\
\text { One on Day } 7 \\
(\mathrm{~N}=25)\end{array}$ & $\begin{array}{c}\text { One Dose } \\
\text { on Day 0, } \\
\text { One on Day } 14 \\
(\mathrm{~N}=25)\end{array}$ & & & & \\
\hline \multicolumn{8}{|l|}{$\begin{array}{c}\text { Race or ethnic group - } \\
\text { no. }(\%)^{*}\end{array}$} \\
\hline White & $21(84)$ & $23(92)$ & $19(76)$ & $20(80)$ & $17(68)$ & $19(76)$ & $25(100)$ \\
\hline South Asian & $4(16)$ & $1(4)$ & $3(12)$ & $4(16)$ & $4(16)$ & $5(20)$ & 0 \\
\hline Black & 0 & 0 & $3(12)$ & $1(4)$ & $3(12)$ & $1(4)$ & 0 \\
\hline Chinese & 0 & $1(4)$ & 0 & 0 & $1(4)$ & 0 & 0 \\
\hline \multicolumn{8}{|l|}{ Sex- no. (\%) } \\
\hline Female & $14(56)$ & $19(76)$ & $15(60)$ & $16(64)$ & $13(52)$ & $20(80)$ & $16(64)$ \\
\hline Male & $11(44)$ & $6(24)$ & $10(40)$ & $9(36)$ & $12(48)$ & $5(20)$ & $9(36)$ \\
\hline $\begin{array}{l}\text { Previous receipt of sea- } \\
\text { sonal influenza } \\
\text { vaccine - no. (\%) }\end{array}$ & $9(36)$ & $11(44)$ & $11(44)$ & $9(36)$ & $7(28)$ & $7(28)$ & $11(44)$ \\
\hline \multicolumn{8}{|l|}{ Age $-y r$} \\
\hline Median & 34 & 32 & 29 & 35 & 31 & 34 & 30 \\
\hline Range & $19-49$ & $18-50$ & $23-49$ & $20-49$ & $20-48$ & $24-49$ & $24-49$ \\
\hline
\end{tabular}

* Race or ethnic group was self-reported.

inhibition and microneutralization assays. Because there are no established immune correlates for microneutralization, in that analysis we assessed the proportion of subjects who had seroconversion (an increase in the antibody titer by a factor of four or more) and a microneutralization titer of 1:40 or more.

\section{RESULTS}

This preliminary report details interim analyses through day 21 after the first vaccination of 100 subjects (four of the seven groups studied) who received two doses of $7.5 \mu \mathrm{g}$ of MF59-adjuvanted vaccine, administered either concurrently at day 0 or as in one injection at day 0 and the other at day 7, 15, or 21 (Fig. 1). We will report the complete findings of this study when the analyses of data from all seven vaccine groups are complete, through the day 42 immunogenicity assessment.

By day 21, a total of 75 subjects had received two doses of $7.5 \mu \mathrm{g}$ of MF59-adjuvanted vaccine (all of whom had their first dose at day 0 and 25 with the second dose on day 0,25 with the second dose on day 7 , and 25 with the second dose on day 14). The remaining 25 subjects had received one dose, with the second dose scheduled for day 21. All subjects received their assigned vaccines, returned all diary cards, and had serum samples obtained at day 21 , according to the protocol. Additional serum specimens were obtained on day 14 from 24 of the 25 subjects (96\%) who had received one dose only and from 72 of the 75 (96\%) who had received both doses. All 100 subjects were included in safety and immunogenicity analyses (Fig. 1).

The median age was 33 years (range, 18 to 50 ), $65 \%$ were female, $82 \%$ were white, and $37 \%$ had previously received seasonal influenza vaccine (Table 1). The baseline characteristics in each group were similar.

\section{SAFETY ANALYSIS}

We studied the reactogenicity after administration of the $7.5 \mu \mathrm{g}$ of MF59-adjuvanted vaccine. Solicited local and systemic reactions during the first 7 days after the first dose of $7.5 \mu \mathrm{g}$ of MF59adjuvanted vaccine are shown in Table 2. Overall, $86 \%$ of subjects reported adverse reactions after either vaccine dose $(85 \%$ after the first and $56 \%$ 
Table 2. Solicited Local and Systemic Adverse Effects within 7 Days after Receipt of Either Dose of $7.5 \mu \mathrm{g}$ of MF59Adjuvanted Vaccine, According to Vaccine Group.*

\begin{tabular}{|c|c|c|c|c|}
\hline \multirow[t]{2}{*}{ Effect } & $\begin{array}{l}\text { One Dose on Day } 0 \\
(N=25) \dagger\end{array}$ & $\begin{array}{l}\text { Both Doses on Day } 0 \\
(\mathrm{~N}=25) \div\end{array}$ & $\begin{array}{l}\text { One Dose on Day 0, } \\
\text { One on Day } 7(N=25)\end{array}$ & $\begin{array}{c}\text { One Dose on Day 0, } \\
\text { One on Day } 14 \\
(N=25)\end{array}$ \\
\hline & \multicolumn{4}{|c|}{ percent ( $95 \%$ confidence interval) } \\
\hline \multicolumn{5}{|l|}{ Local reaction } \\
\hline \multicolumn{5}{|c|}{ Pain at injection site } \\
\hline None & $36(18-58)$ & $16(5-36)$ & $44(24-65)$ & $24(9-45)$ \\
\hline Mild & $60(39-79)$ & $76(55-91)$ & $48(28-69)$ & $48(28-69)$ \\
\hline Moderate & $4(0-20)$ & $8(1-26)$ & $8(1-26)$ & $28(12-49)$ \\
\hline Severe & $0(0-14)$ & $0(0-14)$ & $0(0-14)$ & $0(0-14)$ \\
\hline \multicolumn{5}{|c|}{ Redness diameter } \\
\hline $0 \mathrm{~mm}$ & $96(80-100)$ & $88(69-98)$ & $88(69-98)$ & $84(64-96)$ \\
\hline $1-4 \mathrm{~mm}$ & $0(0-14)$ & $12(3-31)$ & $12(3-31)$ & $16(5-36)$ \\
\hline$\geq 5 \mathrm{~mm}$ & $4(0-20)$ & $0(0-14)$ & $0(0-14)$ & $0(0-14)$ \\
\hline \multicolumn{5}{|c|}{ Swelling diameter } \\
\hline $0 \mathrm{~mm}$ & $96(80-100)$ & $84(64-96)$ & $96(80-100)$ & $80(59-93)$ \\
\hline $1-4 \mathrm{~mm}$ & $4(0-20)$ & $12(3-31)$ & $0(0-14)$ & $16(5-36)$ \\
\hline$\geq 5 \mathrm{~mm}$ & $0(0-14)$ & $4(0-20)$ & $4(0-20)$ & $4(0-20)$ \\
\hline \multicolumn{5}{|c|}{ Bruising diameter } \\
\hline $0 \mathrm{~mm}$ & $96(80-100)$ & 92 (74-99) & $92(74-99)$ & $84(64-96)$ \\
\hline $1-4 \mathrm{~mm}$ & $4(0-20)$ & $4(0-20)$ & $4(0-20)$ & $8(1-26)$ \\
\hline$\geq 5 \mathrm{~mm}$ & $0(0-14)$ & $4(0-20)$ & $4(0-20)$ & $8(1-26)$ \\
\hline \multicolumn{5}{|c|}{ Systemic reaction } \\
\hline \multicolumn{5}{|c|}{ Muscle aches } \\
\hline None & $68(47-85)$ & $36(18-58)$ & $64(43-82)$ & $64(43-82)$ \\
\hline Mild $\sqrt{ }$ & $28(12-49)$ & $52(31-72)$ & $32(15-54)$ & $16(5-36)$ \\
\hline Moderate & $4(0-20)$ & $12(3-31)$ & $4(0-20)$ & $20(7-41)$ \\
\hline Severe & $0(0-14)$ & $0(0-14)$ & $0(0-14)$ & $0(0-14)$ \\
\hline \multicolumn{5}{|l|}{ Chills } \\
\hline None & $96(80-100)$ & $84(64-96)$ & $100(86-100)$ & $88(69-98)$ \\
\hline Mild & $0(0-14)$ & $8(1-26)$ & $0(0-14)$ & $4(0-20)$ \\
\hline Moderate & $4(0-20)$ & $8(1-26)$ & $0(0-14)$ & $8(1-26)$ \\
\hline Severe & $0(0-14)$ & $0(0-14)$ & $0(0-14)$ & $0(0-14)$ \\
\hline \multicolumn{5}{|l|}{ Malaise } \\
\hline None & $84(64-96)$ & $76(55-91)$ & $96(80-100)$ & $88(86-100)$ \\
\hline Mild & $12(3-31)$ & $24(9-46)$ & $4(0-20)$ & $8(1-26)$ \\
\hline Moderate & $4(0-20)$ & $0(0-14)$ & $0(0-14)$ & $4(0-20)$ \\
\hline Severe & $0(0-14)$ & $0(0-14)$ & $0(0-14)$ & $0(0-14)$ \\
\hline \multicolumn{5}{|l|}{ Headache } \\
\hline None & $68(47-85)$ & 60 (39-79) & $80(59-93)$ & $56(35-76)$ \\
\hline Mild & $28(12-49)$ & $36(18-58)$ & $12(3-31)$ & $28(12-49)$ \\
\hline Moderate & $4(0-20)$ & $4(0-20)$ & $8(1-26)$ & $16(5-36)$ \\
\hline Severe & $0(0-14)$ & $0(0-14)$ & $0(0-14)$ & $0(0-14)$ \\
\hline
\end{tabular}




\begin{tabular}{|c|c|c|c|c|}
\hline Table 2. (Continued.) & & & & \\
\hline Effect & $\begin{array}{l}\text { One Dose on Day } 0 \\
(N=25) \dagger\end{array}$ & $\begin{array}{l}\text { Both Doses on Day } 0 \\
\left(\begin{array}{l}(\mathbf{N}=25) \% \\
\text { percent }(95 \% \text { co }\end{array}\right.\end{array}$ & $\begin{array}{l}\text { One Dose on Day 0, } \\
\text { One on Day } 7(\mathrm{~N}=25) \\
\text { nfidence interval) }\end{array}$ & $\begin{array}{l}\text { One Dose on Day 0, } \\
\text { One on Day } 14 \\
(N=25)\end{array}$ \\
\hline \multicolumn{5}{|l|}{ Nausea } \\
\hline None & $80(59-93)$ & $88(69-98)$ & 92 (74-99) & $84(64-96)$ \\
\hline Mild & $12(3-31)$ & $12(3-31)$ & $4(0-20)$ & $12(3-31)$ \\
\hline Moderate & $8(1-26)$ & $0(0-14)$ & $4(0-20)$ & $4(0-20)$ \\
\hline Severe & $0(0-14)$ & $0(0-14)$ & $0(0-14)$ & $0(0-14)$ \\
\hline Fever, temperature $\geq 38^{\circ} \mathrm{C}$ & $0(0-14)$ & $4(0-20)$ & $0(0-14)$ & $4(0-20)$ \\
\hline Use of analgesic & $8(1-26)$ & $20(7-41)$ & $0(0-14)$ & $16(5-36)$ \\
\hline
\end{tabular}

* Subjects used a subjective scale to grade adverse events. Symptoms were considered mild if they did not interfere with daily activities, moderate if they caused some impairment, and severe if they affected daily activities and necessitated medical attention.

$\uparrow$ The group who had received one dose on day 0 had the second dose scheduled for day 21 , but it had not yet been administered.

+ For the group who had received both doses concurrently on day 0 , any local reaction in either arm is reported.

$\int$ Muscle aches were reported significantly more frequently in the group receiving both doses on day 0 than in the other three groups $(P=0.02$ by Fisher's exact test).

after the second). The frequency or severity of reactions did not increase after the second vaccine as compared with after the first (see the Supplementary Appendix). All self-reported reactions were graded as mild or moderate and were generally self-limited, resolving within a 72-hour period.

The most frequent local reaction after any dose of $7.5 \mu \mathrm{g}$ of MF59-adjuvanted vaccine was pain at the injection site, in $70 \%$ of subjects. In general, such pain was not accompanied by redness or swelling, although one subject recorded bruising, in an area $20 \mathrm{~mm}$ in diameter, after the first dose, with resolution within 72 hours. No severe local reactions were reported.

The most frequent systemic reaction was muscle ache, in $42 \%$ of subjects. A total of $11 \%$ of subjects reported using an analgesic for systemic symptoms. Two subjects reported fever, defined as temperature of $38^{\circ} \mathrm{C}$ or more, after receipt of the first dose, but neither used antipyretic medication. In general, the frequency and severity of solicited reactions after injection of the $7.5 \mu \mathrm{g}$ of MF59-adjuvanted vaccine did not differ among the groups, although subjects who received both doses on day 0 reported a greater frequency of systemic reactions (muscle aches) as compared with the other three groups $(\mathrm{P}=0.02)$. No severe systemic reactions were reported.

Seven unsolicited adverse events were reported. Three subjects reported self-limiting diarrhea that resolved within the 48-hour period after the first dose; one subject took over-the-counter loperamide as treatment. Two subjects reported coryza that resolved within 48 hours. One subject reported a toothache that resolved after 5 days. One subject reported a transient itchy rash on the right forearm that resolved within 48 hours (Table 3 in the Supplementary Appendix).

A probable vaccine-related adverse reaction, reported after receipt of the $7.5 \mu \mathrm{g}$ of MF59-adjuvanted vaccine, is described in the Supplementary Appendix. Briefly, this subject (who received two doses of the MF59-adjuvanted vaccine on day 0) reported a purpuric rash on the lower limbs on day 17, with resolution within 72 hours. Further questioning revealed that she had consulted with her family practitioner in May 2009 for an intermittent leg rash within the 12-month period before the study. Investigations including complete blood count and biochemical profile showed normal values, but an autoimmune profile was positive for antinuclear and extractable nuclear-antigen antibodies. She had not received medication, and this previous medical history was not known at enrollment. Follow-up for the rash included a normal complete blood count and biochemical profile. Results of autoimmune testing were unchanged from those in May 2009.

IMMUNOGENICITY AGAINST THE 2009 HINI VIRUS Interim analysis was conducted at day 21 after the first dose of $7.5 \mu \mathrm{g}$ of MF59-adjuvanted vaccine. 


\begin{tabular}{|c|c|c|c|c|}
\hline Value & $\begin{array}{c}\text { One Dose } \\
\text { on Day } 0(N=25) 广\end{array}$ & $\begin{array}{l}\text { Both Doses on } \\
\text { Day } 0(\mathrm{~N}=25)\end{array}$ & $\begin{array}{c}\text { One Dose } \\
\text { on Day 0, } \\
\text { One on Day } 7 \\
(N=25)\end{array}$ & $\begin{array}{c}\text { One Dose } \\
\text { on Day 0, } \\
\text { One on Day } 14 \\
(N=25)\end{array}$ \\
\hline \multicolumn{5}{|l|}{ Day 0} \\
\hline Geometric mean titer $(95 \% \mathrm{Cl})$ & $6.2(4.0-9.4)$ & $6.0(3.8-9.5)$ & $4.8(3.7-6.3)$ & $6.6(4.2-10.4)$ \\
\hline Seroprotection — \% $(95 \% \mathrm{Cl})$ & $12(3-31)$ & $8(1-26)$ & $4(0-20)$ & $12(3-31)$ \\
\hline \multicolumn{5}{|l|}{ Day $14 \nmid$} \\
\hline Geometric mean titer $(95 \% \mathrm{Cl})$ & $195.6(88.8-431.0)$ & $294.8(165.9-523.5)$ & $416.5(260.9-664.9)$ & $155.8(62.7-387.2)$ \\
\hline Geometric mean ratio $(95 \% \mathrm{Cl})$ & $31.7(13.7-73.5)$ & $49.2(24.6-98.2)$ & $86.7(52.3-143.8)$ & $23.7(8.9-62.2)$ \\
\hline Seroconversion — \% (95\% Cl) & $79(58-93)$ & 91 (72-99) & $96(79-100)$ & $68(47-85)$ \\
\hline Seroprotection — \% $(95 \% \mathrm{Cl})$ & $83(63-95)$ & $96(78-100)$ & $100(86-100)$ & $72(51-88)$ \\
\hline \multicolumn{5}{|l|}{ Day 21} \\
\hline Geometric mean titer $(95 \% \mathrm{Cl})$ & $172.5(80.2-370.8)$ & $256.1(158.0-415.2)$ & $282.9(160.2-499.7)$ & $288.7(150.6-553.7)$ \\
\hline Geometric mean ratio $(95 \% \mathrm{Cl})$ & $27.9(12.2-64.2)$ & $42.7(22.7-80.5)$ & $58.9(32.4-107.0)$ & $43.8(20.6-93.2)$ \\
\hline Seroconversion — \% (95\% Cl) & $76(55-91)$ & $88(69-98)$ & $92(74-99)$ & $88(69-98)$ \\
\hline Seroprotection — \% $(95 \% \mathrm{Cl})$ & $80(59-93)$ & $92(74-99)$ & $96(80-100)$ & $92(74-99)$ \\
\hline \multicolumn{5}{|c|}{$\begin{array}{l}\text { * Geometric mean titers are the ratios of the antibody level at the day of interest and at day } 0 \text {. Percentages of subjects } \\
\text { are based on the total number of subjects tested. Seroprotection was defined as an antibody titer of } 1: 40 \text { or more. } \\
\text { Seroconversion was defined as prevaccination antibody titer of } 1: 10 \text { or less and a postvaccination titer of } 1: 40 \text { or more } \\
\text { or a prevaccination titer greater than } 1: 10 \text { and an increase in the antibody titer by a factor of four or more. } \\
+ \text { The group that had received one dose on day } 0 \text { had the second dose scheduled for day } 21 \text {, but it had not yet been ad- } \\
\text { ministered. } \\
\text { At day } 14 \text {, the geometric mean ratio, the rate of seroconversion, and the rate of seroprotection were all significantly } \\
\text { greater }(P=0.04, P=0.01 \text {, and } P=0.04 \text {, respectively) in the two groups that had received two doses (the first dose on } \\
\text { day } 0 \text { and the second dose on day } 0 \text { or day } 7) \text { as compared with the two groups that had received one dose only (with } \\
\text { the second dose scheduled for day } 14 \text { or day } 21) \text {. }\end{array}$} \\
\hline
\end{tabular}

Antibody responses against the vaccine were measured for each of the four groups.

Antibodies were detected, as measured by hemagglutination-inhibition assay (titer $>1: 8$ ) and microneutralization assay (titer $>1: 10$ ) before vaccination in $14 \%$ and $39 \%$ of subjects, respectively, with this frequency unrelated to age $(\mathrm{P}=0.91$ by hemagglutination-inhibition assay and $\mathrm{P}=0.48$ by microneutralization assay) or previous receipt of seasonal vaccine $(\mathrm{P}=0.15$ and $\mathrm{P}=0.39$, respectively).

On day 14 , geometric mean titers, as measured with the use of hemagglutination-inhibition assay (Table 3) and microneutralization assay (Table 4), were higher in subjects who received two doses of $7.5 \mu \mathrm{g}$ of MF59-adjuvanted vaccine by this time, as compared with those who had received one dose only ( $\mathrm{P}=0.04$ by hemagglutination-inhibition assay and $\mathrm{P}<0.001$ by microneutralization assay), but there was no significant difference in titer among the groups $(\mathrm{P}=0.34$ by hemagglutination-inhibition assay and $\mathrm{P}=0.10$ by microneutralization assay). On day 21 , there was no significant difference in titer among subjects who had received one dose of $7.5 \mu \mathrm{g}$ of MF59adjuvanted vaccine and those who had received two $(\mathrm{P}=0.18$ by hemagglutination-inhibition assay and $\mathrm{P}=0.051$ by microneutralization assay).

Table 3 shows the ratio of antibody titer after first vaccination and before first vaccination and the percentages of subjects with seroconversion and seroprotection, as measured by means of the hemagglutination-inhibition assay. On day 14, the rates of seroconversion and seroprotection were higher $(\mathrm{P}=0.01$ and $\mathrm{P}=0.004$, respectively) among subjects who had two doses than among those who had only one. On day 21 , there was no significant difference in the rate of seroconversion $(\mathrm{P}=0.11)$ or seroprotection $(\mathrm{P}=0.12)$ among those who had received one and those who had received two doses.

There was also no significant difference in the rate of seroconversion between subjects who had antibody detected at baseline and those who did 


\begin{tabular}{|c|c|c|c|c|}
\hline Value & $\begin{array}{l}\text { One Dose } \\
\text { on Day } 0 \\
(N=25) \dot{7}\end{array}$ & $\begin{array}{c}\text { Both Doses on } \\
\text { Day } 0 \\
(\mathrm{~N}=\mathbf{2 5})\end{array}$ & $\begin{array}{c}\text { One Dose } \\
\text { on Day 0, } \\
\text { One on Day } 7 \\
(\mathrm{~N}=25)\end{array}$ & $\begin{array}{c}\text { One Dose } \\
\text { on Day 0, } \\
\text { One on Day } 14 \\
(N=25)\end{array}$ \\
\hline \multicolumn{5}{|l|}{ Day 0} \\
\hline Geometric mean titer $(95 \% \mathrm{CI})$ & $13.4(8.2-21.9)$ & $10.4(5.9-18.1)$ & $9.8(6.6-14.5)$ & $13.1(7.8-22.1)$ \\
\hline Antibody titer $\geq 40-\%(95 \% \mathrm{Cl})$ & $20(7-41)$ & $12(3-31)$ & $16(5-36)$ & $16(5-36)$ \\
\hline \multicolumn{5}{|l|}{ Day 14} \\
\hline Geometric mean titer $(95 \% \mathrm{Cl}) ‡$ & $353.3(256.5-486.5)$ & $606.5(557.8-659.5)$ & $502.2(406.7-622.6)$ & $285.4(185.1-439.9)$ \\
\hline Seroconversion — \% $(95 \% \mathrm{Cl})$ & $83(63-95)$ & 91 (72-99) & $96(79-100)$ & $84(64-96)$ \\
\hline Antibody titer $\geq 40-\%(95 \% \mathrm{Cl})$ & $100(86-100)$ & $100(85-100)$ & $100(86-100)$ & 92 (74-99) \\
\hline \multicolumn{5}{|l|}{ Day 21} \\
\hline Geometric mean titer $(95 \% \mathrm{Cl})$ & $348.2(247.3-490.3)$ & $582.8(518.3-655.3)$ & $448.9(335.1-601.5)$ & $407.2(301.4-550.3)$ \\
\hline Seroconversion — \% $(95 \% \mathrm{Cl})$ & 92 (74-99) & 92 (74-99) & $96(80-100)$ & $96(80-100)$ \\
\hline Antibody titer $\geq 40-\%(95 \% \mathrm{Cl})$ & $100(86-100)$ & $100(86-100)$ & $100(86-100)$ & $100(86-100)$ \\
\hline
\end{tabular}

* Percentages of subjects are based on the total number of subjects tested. Because no threshold titer for seroprotection has been established for the microneutralization assay, the percentage of subjects with titers of 1:40 or greater are reported. "Antibody titer $\geq 40$ " denotes a titer of 1:40 or greater at each postvaccination visit. Seroconversion was defined as an increase in the antibody titer by a factor of four or more.

$\dagger$ The group who had received one dose on day 0 had the second dose scheduled for day 21 , but it had not yet been administered.

$\$$ At day 14 , the geometric mean ratio was significantly greater $(P=0.04)$ in the two groups who had received two doses (the first dose on day 0 and the second dose on day 0 or day 7 ) as compared with the two groups that had received one dose only (with the second dose scheduled for day 14 or day 21 ).

not $(\mathrm{P}=0.68$ by the hemagglutination-inhibition assay and $\mathrm{P}=0.66$ by the microneutralization assay). Because various dosing intervals were evaluated, postvaccination responses at specific time points may not reflect overall antibody kinetics.

Table 4 shows the percentages of subjects with seroconversion and antibody titers exceeding 1:40, as measured by means of the microneutralization assay. On days 14 and 21, there was no significant difference among the vaccine groups in the rate of seroconversion (day $14, \mathrm{P}=0.20$; day $21, \mathrm{P}=0.64$ ) or those with titers exceeding 1:40 (day $14, \mathrm{P}=0.50$; day $21, \mathrm{P}=1.00$ ). Figure 2 shows the distribution of antibody titers at day 21 after the first dose, according to vaccine group. Titers of the hemagglutination-inhibition antibody exceeded 1:32 in $88 \%$ of subjects who had received one vaccine dose by this time and in 92 to $100 \%$ of subjects who had received both doses (Fig. 2A). All subjects had microneutralization antibody at a titer exceeding 1:40 by day 21 (Fig. 2B).

Responses, as measured with the use of hemagglutination-inhibition assay, against the NIBRG-121 virus were similar to those against the $2009 \mathrm{H} 1 \mathrm{~N} 1$ virus (see the Supplementary Appendix).

\section{DISCUSSION}

This report details the interim findings for subjects receiving the 7.5- $\mu \mathrm{g}$ dose of the MF59-adjuvanted vaccine. We found that the immune responses were consistent with seroprotection against the 2009 pandemic influenza A (H1N1) virus within 2 weeks after administration of a single dose of the adjuvanted cell-culture vaccine. Data for the recipients of nonadjuvanted vaccine will be reported when analysis is completed.

Effective vaccination should reduce morbidity, mortality, and virus transmission, ${ }^{4}$ although this is challenging to achieve. The global demand for vaccine will likely exceed manufacturing capacity and will only be met by implementing a range of approaches to vaccine development. Large-scale vaccine production with the use of newly characterized viruses can be challenging if low egg growth limits the supply of antigen. Our vaccine was produced from a classical egg-derived seed virus propagated in a MDCK cell line.,21 Cellculture systems may provide a faster response and potentially greater scale-up than egg production. Cell-culture seasonal influenza seed viruses also 
* One dose on day $0 \multimap$ Two doses, one on day 0 and one on day 7

$\rightarrow$ Two doses on day $0 \rightarrow$ Two doses, one on day 0 and one on day 14

\section{A Hemagglutination-Inhibition Titer}

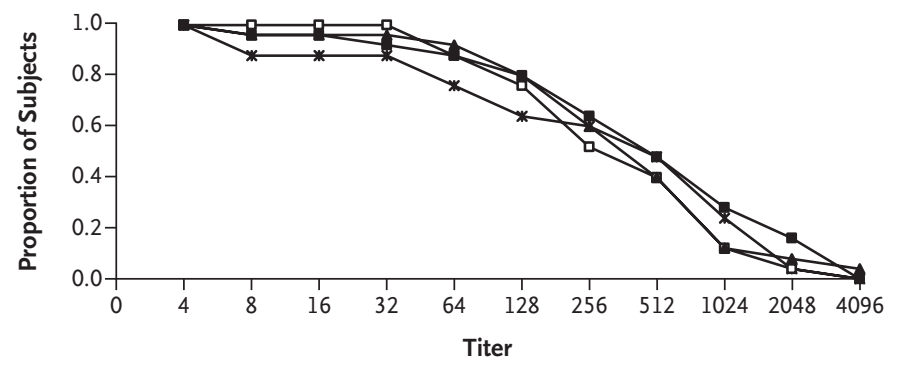

B Microneutralization Titer

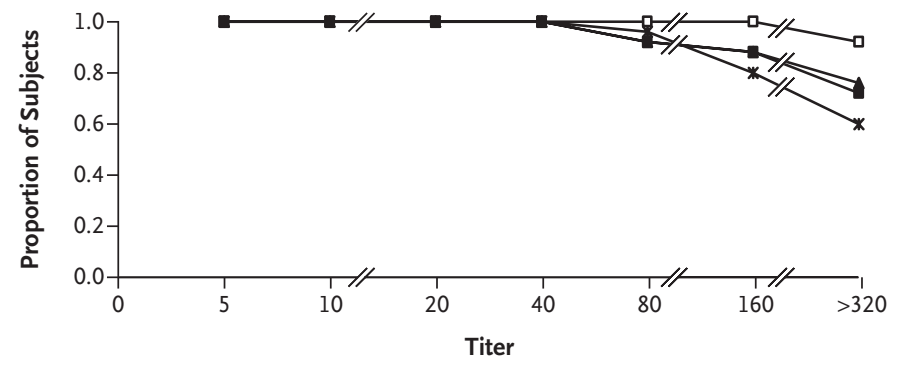

Figure 2. Reverse Cumulative-Distribution Curves of Antibody Titers in Serum Samples Obtained on Day 21 after First Dosing of $7.5 \mu \mathrm{g}$ of MF59Adjuvanted Vaccine, According to Number and Timing of Doses.

The percentages of subjects are based on the total number of subjects tested in the four vaccine groups. All four groups received the first of two doses on day 0 . Three of the groups had received the second dose (on day 0 , day 7 , or day 14); one group had yet to receive the second dose (scheduled for day 21). Panel A shows the results of hemagglutination-inhibition assays, and Panel B shows the results of microneutralization assays. Titers are expressed as the reciprocal of the dilution. show better antigenic matching to clinical isolates than egg-passaged vaccine strains. ${ }^{5-8,21}$

Clinical experience with avian and human influenza $\mathrm{A} / \mathrm{H} 1 \mathrm{~N} 1-$ subunit vaccines in immunologically naive subjects who had little evidence of cross-reactive antibodies suggests that two doses are required to induce seroprotection. ${ }^{10-15,22,23}$ Traditionally, dosing intervals of 21 to 28 days are used, often delaying effective immunization. In our interim analysis, we report data on several immunization schedules involving two 7.5- $\mu \mathrm{g}$ doses of MF59-adjuvanted vaccine. Flexible dosing would be useful for authorities organizing immunization regimens, although a single vaccination against the 2009 pandemic influenza A (H1N1) virus would be logistically most desirable.

Our findings add to observations that oil-inwater-emulsion adjuvants have short-term reacto- genicity equivalent to that of inactivated seasonal vaccines. ${ }^{24}$ Although adjuvants generally enhance immunogenicity, their effect on the 2009 H1N1 virus is unknown. Our head-to-head evaluation with nonadjuvanted formulations will assess the effect of adding MF59 adjuvant on the speed and magnitude of antibody responses. For avian-influenza subvirion vaccines, oil-in-water-emulsion adjuvants are essential to inducing long-lasting cross-reactive immunity. ${ }^{10,12-15}$ Although influenza A (H1N1) virus isolates are antigenically homogeneous, the induction of antibody that is crossreactive to drift variants would be a desirable characteristic of the first vaccines against the 2009 H1N1 virus.

Interpretation of immunogenicity data for the vaccine against the 2009 pandemic influenza $\mathrm{A}$ (H1N1) virus is complicated by a lack of recognized immune correlates. The insensitivity of hemagglutination-inhibition assays to some avian hemagglutinin has required that microneutralization assays, hemagglutination-inhibition assays involving horse erythrocytes, or single radial hemolysis be used. ${ }^{10,18,25}$ Because there is significant laboratory variation in testing, ${ }^{20}$ efforts to develop biologic standards for serologic assays of influenza A (H1N1) viruses are under way. Fifteen percent of subjects had detectable prevaccination levels of hemagglutination-inhibition antibody, consistent with results of seroepidemiologic studies. ${ }^{11}$ Although we excluded subjects with previous respiratory illnesses, asymptomatic infection with influenza A (H1N1) viruses cannot be ruled out, as local activity was present during the study.

The safety and immunogenicity of these and alternative candidate vaccines against the 2009 H1N1 virus, including egg-derived, whole-virion, recombinant, and live-attenuated vaccines must be assessed in high-risk populations, including children, the elderly, and other persons whose immunologic profiles may differ from those of young adults. ${ }^{8}$ In addition, the duration of antibody responses and their ability to be boosted after revaccination should be established to predict protection against future pandemic waves.

Finally, although seasonal influenza vaccines have an established safety profile, there are occasional case reports of unusual reactions, including vasculitis. ${ }^{24,26}$ MF59, a proprietary oil-in-wateremulsion adjuvant, was first licensed for use in seasonal influenza vaccines in 1997. Over 40 million doses have been delivered in Europe, and over 16,000 doses administered in clinical trials, with 
no excess reports of autoimmune conditions. ${ }^{27}$ It is important to ensure post-marketing surveillance during any mass use of a pandemic-virus vaccine, with or without adjuvant.

This preliminary report of vaccines against the 2009 pandemic influenza A (H1N1) virus with or without MF59 will be updated as analyses are completed but may be useful for the planning of immunization schedules and future trials and comparisons with other vaccine options as they become available.

Supported by grants from University Hospitals Leicester and Novartis.
Dr. Hoschler reports holding equity and stock options in Illumina; Dr. Nicholson, receiving consulting fees from Novartis Vaccines and GlaxoSmithKline and lecture fees from Baxter Vaccines; Dr. Groth, holding equity and stock options in Novartis; and Dr. Stephenson, receiving consulting fees from Novartis Vaccines and Sanofi Pasteur, lecture fees from Baxter Vaccines and Novartis Vaccines, and grant support from Hoffmann-La Roche, Novartis Vaccines, and GlaxoSmithKline. No other potential conflict of interest relevant to this article was reported.

We thank the subjects who volunteered for the study and staff at University Hospitals of Leicester Infectious Diseases Research Unit, Department for Research and Development, and Leicestershire Comprehensive Research Network Office; the clinical investigator team at Novartis Vaccines and Diagnostics for their regulatory support of the study; and the technical staff at the Health Protection Agency influenza laboratory for providing assistance with serologic assessments.

\section{REFERENCES}

1. Global alert and response: Pandemic (H1N1) 2009. Geneva: World Health Organization, 2009. (Accessed September 10, 2009, at http://www.who.int/csr/disease/ swineflu/en.)

2. Novel Swine-Origin Influenza A (H1N1) Virus Investigation Team. Emergence of a novel swine-origin influenza A (H1N1) virus in humans. N Engl J Med 2009;360 2605-15.

3. Perez-Padilla R, de la Rosa-Zamboni $\mathrm{D}$, Ponce de Leon S, et al. Pneumonia and respiratory failure from swine-origin influenza A (H1N1) in Mexico. N Engl J Med 2009;361:680-9.

4. Ferguson NM, Cummings DA, Fraser C, Cajka JC, Cooley PC, Burke DS. Strategies for mitigating an influenza pandemic. Nature 2006;442:448-52.

5. Oxford JS, Manuguerra C, Kistner O, et al. A new European perspective of influenza pandemic planning with a particular focus on the role of mammalian cell culture vaccines. Vaccine 2005;23:5440-9.

6. Audsley JM, Tannock GA. Cell-based influenza vaccines: progress to date. Drugs 2008;68:1483-91

7. Szymczakiewicz-Multanowska A, Groth N, Bugarini R, et al. Safety and immunogenicity of a novel influenza subunit vaccine produced in mammalian cell culture. J Infect Dis 2009;200:841-8.

8. Serum cross-reactive antibody response to a novel influenza A (H1N1) virus after vaccination with seasonal influenza vaccine. MMWR Morb Mortal Wkly Rep 2009; 58:521-4.

9. Kelly H, Grant K. Interim analysis of pandemic influenza (H1N1) 2009 in Australia: surveillance trends, age of infection and effectiveness of seasonal vaccination. (Accessed September 10, 2009, at http://www.eurosurveillance.org/ ViewArticle.aspx?ArticleId=19288.)

10. Nicholson KG, Colegate AC, Podda A, et al. Safety and antigenicity of non-adjuvant- ed and MF59-adjuvanted influenza A/Duck/ Singapore/97 (H5N3) vaccine: a randomised trial of two potential vaccines against $\mathrm{H} 5 \mathrm{~N} 1$ influenza. Lancet 2001;357:1937-43.

11. Treanor JJ, Campbell JD, Zangwill KM, Rowe T, Wolff M. Safety and immunogenicity of an inactivated subvirion influenza A (H5N1) vaccine. N Engl J Med 2006;354:1343-51.

12. Atmar RL, Keitel WA, Patel SM, et al. Safety and immunogenicity of nonadjuvanted and MF59-adjuvanted influenza A/ H9N2 vaccine preparations. Clin Infect Dis 2006;43:1135-42.

13. Stephenson I, Nicholson KG, Glück R, et al. Safety and antigenicity of whole virus and subunit influenza A/Hong Kong/ 1073/99 (H9N2) vaccine in healthy adults: phase I randomised trial. Lancet 2003; 1959-66.

14. Stephenson I, Bugarini R, Nicholson $\mathrm{KG}$, et al. Cross-reactivity to highly pathogenic avian influenza H5N1 viruses after vaccination with nonadjuvanted and MF59adjuvanted influenza A/Duck/Singapore/97 (H5N3) vaccine: a potential priming strategy. J Infect Dis 2005;191:1210-5.

15. Leroux-Roels I, Borkowski A, Vanwolleghem $\mathrm{T}$, et al. Antigen sparing and cross-reactive immunity with an adjuvanted $\mathrm{rH} 5 \mathrm{~N} 1$ prototype pandemic influenza vaccine: a randomised controlled trial. Lancet 2007;370:580-9.

16. Galli G, Hancock K, Hoschler K, et al. Fast rise of broadly cross-reactive antibodies after boosting long-lived human memory B cells primed by an MF59 adjuvanted prepandemic vaccine. Proc Natl Acad Sci U S A 2009;106:7962-7.

17. Global alert and response: WHO recommendations on pandemic (H1N1) 2009 vaccines. Geneva: World Health Organization, 2009. (Accessed September 10, 2009, at http://www.who.int/csr/disease/ swineflu/notes/h1n1_vaccine_20090713/ en/index.html.)
18. Rowe T, Abernathy RA, Hu-Primmer J, et al. Detection of antibody to avian influenza A (H5N1) virus in human serum by using a combination of serologic assays. J Clin Microbiol 1999;37:937-43.

19. Ellis JS, Zambon MC. Molecular investigation of an outbreak of influenza in the United Kingdom. Eur J Epidemiol 1997;13: 369-72.

20. Stephenson I, Heath A, Major D, et al. Reproducibility of serologic assays for influenza virus A (H5N1). Emerg Infect Dis 2009 August (Epub ahead of print).

21. Doroshenko A, Halperin SA. Trivalent MDCK cell culture-derived influenza vaccine Optaflu (Novartis Vaccines). Expert Rev Vaccines 2009;8:679-88.

22. Nicholson KG, Tyrrell DA, Harrison P, et al. Clinical studies of monovalent inactivated whole virus and subunit A/USSR/77 (H1N1) vaccine: serological responses and clinical reactions. J Biol Stand 1979;7:12336.

23. Parkman PD, Hopps HE, Rastogi SC Meyer HM Jr. Summary of clinical trials of influenza virus vaccine in adults. J Infect Dis 1977;136 Suppl:S422-S430.

24. Wiselka MJ. Vaccine Safety. In: Nicholson KG, Hay AJ, Webster RG, eds. Textbook of influenza. Oxford: Blackwell Publications, 1998:346.

25. Stephenson I, Wood JM, Nicholson KG, Zambon MC. Sialic acid receptor specificity on erythrocytes affects detection of antibody to avian influenza haemagglutinin. J Med Virol 2003;70:391-8. 26. Mader R, Narendran A, Lewtas J, et al. Systemic vasculitis following influenza vaccination - report of 3 cases and literature review. J Rheum 1993;20:1429-31. 27. Schultze V, D'Agosto V, Wack A, Novicki D, Zorn J, Hennig R. Safety of MF59 adjuvant. Vaccine 2008;26:3209-22. Copyright (c) 2009 Massachusetts Medical Society. 